\title{
AS TUTELAS DE URGENCIA NO NOVO CÓDIGO DE PROCESSO CIVIL
}

Rachel Lopes Queiroz Chacur

Universidade do Oeste Paulista - UNOESTE. Curso de Direito, Presidente Prudente - SP. E-mail: $\underline{\text { rachel@unoeste.br }}$

\section{RESUMO}

A Reforma do Código de Processo Civil brasileiro traz à baila o tema da autonomia de um Livro e Capítulo "Da Tutela Cautelar" e demais medidas de urgência, no Código de Processo Civil. O presente artigo científico aborda a evolução histórica do Direito Processual Civil Brasileiro e as legislações brasileiras pertinentes até a análise do Projeto e Ante-Projeto do Novo Código de Processo Civil brasileiro.

Palavra-chave: Tutelas Cautelares, Tutelas de urgência, Processo Civil.

\section{URGENT GUARDIANSHIPS AS IN THE NEW CODE OF CIVIL PROCEDURE}

\section{ABSTRACT}

The Reform of the Code of Civil Procedure brings up the issue of autonomy and a Book Chapter "The Trusteeship Injunction" and other emergency measures, the Code of Civil Procedure. This research paper discusses the historical evolution of the Brazilian Civil Procedure and the relevant Brazilian laws by the analysis of the Project and Preliminary Design of the New Code of Civil Procedure.

Keywords: Precautionary Guardianships, Guardianship of urgency Civil Procedure. 


\section{INTRODUÇÃO}

A previsão normativa, em Livros próprios que versam, de forma autônoma, as Tutelas de Evidência e as Tutelas de Urgência, no Anteprojeto e Projeto de Reforma do Código de Processo Civil confirmam a garantia do instrumento processual. Naquilo que concerne a temática "Das Tutelas de Urgência", há um desafio a ser solucionado culminando com as conclusivas da inclusão ou exclusão de um Livro próprio sobre o binômio da temática das Tutelas de Urgência e Tutelas de Evidências. Senão, qual seria a utilidade da distinção das Tutelas de Evidência e Tutelas de Urgência, no Projeto de Reforma do Código de Processo Civil.

O debate diferencia o tratamento processual das Tutelas de Urgência das Tutelas de Evidência, nos divergentes, respectivamente, Projeto, Anteprojeto e Substitutivo de Reforma do Código de Processo Civil. Assim, resta a indagação sobre o restabelecimento do conteúdo meritório do apresentado Projeto de Reforma do Código de Processo Civil, o qual mantém um Livro próprio "Das Tutelas de Urgência" e prevê as demais medidas de urgências contemporizadas no Procedimento de Conhecimento ou nos Procedimentos Específicos. Os debates sobre a Reforma do Código de Processo Civil estabelecem opiniões contrárias à respeito da autonomia das matérias elencadas nos Livros e seus capítulos ou na continuidade de medidas protetivas genéricas, no Rito Comum.

Vale ressaltar, a importância da discussão contínua e democrática das frentes de trabalhos das Comissões reformadoras, em particular, àquela primeiramente proposta. O cotejo da retomada de debates pretende apresentar uma proposta adequada para a eficiente prestação de serviços jurisdicionais, um ordenamento jurídico sistematizado e didático para os operadores do direito, promovendo o alcance do resultado prático e entrega da tutela de direito.

\section{REVISÃO DE LITERATURA}

As Reformas do Código de Processo Civil previram o instituto das Tutelas Jurisdicionais Diferenciadas.

As tutelas jurisdicionais diferenciadas prevêem uma adequação do pedido, em caráter de urgência, para àquelas hipóteses não previstas no rito próprio e que não tinham respaldo legal.

As correntes teóricas cristalizaram os entendimentos técnicos à respeito do tema, o que atualmente é praxe no contexto da prática forense. 
Ocorre que, os institutos cotejados como a Tutela Cautelar, a Tutela Antecipada e o Mandado de Segurança (alteração legislativa recente), não trouxeram respaldo para todas as questões emergentes da sociedade brasileira.

Destarte, surgem situações emergenciais e novas que merecem uma interpretação formal e substancial, para que o Juiz aplique ao caso prático a adequada norma e resolva o conflito de interesses.

Na linha temporal de criação dos institutos processuais, surgiram as classificações de tutelas de urgência: Tutelas Específicas, Tutelas Inibitórias, as Tutelas de Evidência; esta analisada no Projeto de Reforma do Código de Processo Civil.

Apresentou o Projeto, no Livro I, Parte Geral, Título X, em Capitulo próprio da "Tutela de Urgência e Tutela da Evidência".

Art. 277. A tutela de urgência e a tutela da evidência podem ser requeridas antes ou no curso do procedimento, sejam essas medidas de natureza cautelar ou satisfativa.

Art. 278. O juiz poderá determinar as medidas que considerar adequadas quando houver fundado receio de que uma parte, antes do julgamento da lide, cause ao direito da outra lesão grave e de difícil reparação.

Parágrafo único. A medida de urgência poderá ser substituída, de ofício ou a requerimento de qualquer das partes, pela prestação de caução ou outra garantia menos gravosa para o requerido, sempre que adequada e suficiente para evitar a lesão ou repará-la integralmente.

O texto legal descreve que tal decisão concedida no transcorrer do procedimento, em 1a ou 2a Instância, e, é impugnável por Agravo de Instrumento. Naquilo que couber, os mesmos parâmetros de efetivação da medida concessiva da execução provisória e seus efeitos, conforme o atual Código de Processo Civil.

O conteúdo meritório da reforma do Código de Processo Civil foi alterado pela apresentação do Ante-Projeto em andamento e em debates na Câmara dos Deputados e no Senado, em que separa o Livro, nas matérias Tutela de Urgência e Tutela de Evidência, no que segue:

O artigo 285. Será dispensada a demonstração de risco de dano irreparável ou de difícil reparação quando:

I - ficar caracterizado o abuso de direito de defesa ou o manifesto propósito protelatório do requerido;

II - um ou mais dos pedidos cumulados ou parcela deles mostrar-se incontroverso, caso em que a solução será definitiva;

III - a inicial for instruída com prova documental irrefutável do direito alegado pelo autor a que o réu não oponha prova inequívoca; ou 
IV - a matéria for unicamente de direito e houver jurisprudência firmada em julgamento de casos repetitivos ou súmula vinculante.

Parágrafo único. Independerá igualmente de prévia comprovação de risco de dano a ordem liminar, sob cominação de multa diária, de entrega do objeto custodiado, sempre que o autor fundar seu pedido reipersecutório em prova documental adequada do depósito legal ou convencional.

Para Fux (1996, p-317), a características que justificam a concessão da tutela de evidências são o direito demonstrável prima facie por meio de prova documental que demonstre direito líquido e certo, direito baseado em fatos incontroversos e notórios que independam de provas, direito a coibir conduta contra legem, o direito baseado em prova emprestada e garantida pelo crivo da ampla defesa e contraditório, o direito decorrente de prescrição e decadência, entre outros.

Mesmo com as propositivas tutelas, ainda restam situações fáticas não previstas no ordenamento jurídico, da qual se denota independente de respaldo legal, de proteção jurídica e entrega do objeto de direito.

Tais separações de livros e respectivas matérias abordam a concepção de que para a Tutela de Evidência, não há a necessidade do perigo da demora, concluindo pela desclassificação de tal tutela, em tutela de urgência. A Tutela de Evidência seria considerada simplesmente uma medida satisfativa, sem o condão da urgência e provisoriedade das tutelas de urgência.

Nesse mesmo diapasão, outros proponentes do Projeto, em debate, classificam as Tutelas de Urgência, em Tutela Antecipada e Tutela Cautelar; excluindo a Tutela de Evidência, representada por Ada Pelegrini Grinover.

Para alguns doutrinadores, a substituição do texto legal do Anteprojeto pelo Projeto de Reforma do Código de Processo Civil foi um retrocesso no âmbito legislativo processual.

As alterações legislativas debatidas levarão à antinomia legal e anomia dos conflitos sociais e jurídicos, não correspondendo a efetivação das garantias de efetivação dos direitos individuais e/ou coletivos, restando situações fáticas previsíveis, porém não observadas pela atual proposta reformista.

Como dizia Norberto Bobbio (2010, p- 80), a luta pelo direito, mormente foi vencida por e imperará um retrocesso nas já reconhecidas garantias constitucionais do devido e justo processo.

Neste diapasão, resta a assertiva do restabelecimento do proposto tema à contento representados pelos renomados proponentes Luiz Fux e Teresa Arruda Alvim Wambier. A retomada dos debates sob os ditâmes das Tutelas Diferenciadas colaborará para com a potencialização de institutos processuais, bem como resgatando a Tutela Monitória e a Tutela 
Antecipada. Também permitiria a criação da Tutela de Evidência somente para as hipóteses, em que haja a demonstração de direito evidente e conteúdo probatório documentado, tal como acontece com o direito líquido e certo, nos casos específicos, em que cabem o Mandado de Segurança. Ainda, propiciaria a aceleração do provimento jurisdicional e a concessão de medidas de urgências (no sentido lato) para adequações fáticas que merecem pronto atendimento, porém, ainda não observadas em fundamentos de Rito próprio ou específico.

De tal sorte, os julgados dos Tribunais Superiores correlacionam exemplos práticos que versam sobre temas em debates ou direitos novos, os quais estão pautados de forma insuficiente no Código de Processo Civil ou não estão amparados pelo ordenamento pátrio.

O repertório legal das medidas preventivas, no Brasil e alhures, é sabidamente insatisfatório; e, por paradoxal que possa afigurar-se, a sua pobreza agrava-se justamente no domínio onde mais aguda se faz a necessidade prática da tutela: para proteger a posse e a propriedade ainda se dispõe de remédios prestadios, mas a farmacopéia jurídica chega em geral às raias da penúria no que concerne às relações não patrimoniais - precisamente numa área de problemas cuja solução, sem tais remédios, oscila entre os níveis da precariedade e da mistificação (MOREIRA, 1980. p. 3-20.)

Vislumbra-se com a concepção reformista manter a evolução da técnica processual, mantendo e ampliando as garantias constitucionais e cumprindo com os enunciados da Emenda no 45/2004, assim como com as metas elencadas pelo Conselho Nacional de Justiça (CNJ).

\section{CONCLUSÃO}

Nesse contexto, o presente artigo defende a observância do reabertura do debate do texto legal das tutelas diferenciadas, para a consecução dos objetivos e fins da Jurisdição, e, principalmente, enfatiza a necessidade da mantença da premissa garantística do acesso à ordem jurídica justa e a pronta prestação jurisdicional, no bojo da norma infraconstitucional.

A Reforma do Código de Processo Civil brasileiro deve estar em consonância com a moderna exegese do principiológica do Direito Processual Civil Moderno, restando analisar o grau de eficácia e imperatividade das medidas processuais de cognição não exauriente.

\section{REFERÊNCIAS}

BARASSI L. "La Teoria Generale delle Obbligazioni". Milano, Giufrè, 1964, p. 428 e 429.

BAHIA, A.G.M.F. 2007. Interesse público e interesse privado nos recursos extraordinários: por uma compreensão adequada no Estado Democrático de Direito. Belo Horizonte, MG. Tese de Doutorado. UFMG, $248 \mathrm{p}$. 
BENDER, R.; STRECKER, C. 1978. Access to justice in the Federal Republic of Germany. In: M. CAPPELLETTI; B. GARTH, Access to justice - a world survey. Milano, Giuffrè, vol. I, livro II.

CAPPELLETTI, Mauro; GARTH, Bryant. Acesso à Justiça. Trad. Ellen Gracie Northfleet. Porto Alegre: Sergio Antonio Fabris, 2002.

COMOGLIO, L.P. 1988. Etica e tecnica del "giusto processo". Torino, G. Giappichelli.

'giusto processo' civile in Italia. Revista de Processo, II, 2004-a, 116:154-158.

Etica e tecnica del "giusto processo". Torino, G.Giappichelli, 2004-b, 429 p.

La garanzia costituzionale dell'azione ed il processo civile. Padova, Cedam, 1970, 370 p.

CRUZ E TUCCI, José Rogério. A causa petendi no processo civil. 2a ed, São Paulo: Revista dos Tribunais, 2001.

DIDIER JR., Fredie. Curso de Direito Processual Civil. 6ạ edição, v.2, 2010.

DINAMARCO, Candido Rangel. A Instrumentalidade do Processo. 10ạ ed. São Paulo: Malheiros, 2002.

FAZZALARI, E. 1958. Diffusione del processo e compiti della dottrina. Rivista trimestrale di diritto e procedura civile, 3:861-880.

FRIGNANI A. "L'injunction nella "common law" e l'inibitoria nel diritto italiano", cit., p. 465.

FUX, Luiz. Tutela de Segurança e Tutela da Evidência (fundamentos da tutela antecipada). São Paulo: Saraiva, 1996.

A reforma do processo Civil. Niteroi: Impetrus, 2006.

A tutela dos direito evidentes. Revista de Jurisprudencia do STJ (Brasília). Vol.2, 2012. p- 23-43.

HABERMAS, J. 2002. Verdad y justifi cación. Madrid, Trotta, 326 p.

HART, H.L.A. 1963. Law, liberty, and morality. Stanford, Stanford University Press, 88 p.

JUNIOR, Nelson Nery; WAMBIER. Tereza Arruda Alvim. Aspectos polêmicos e atuais dos recursos cíveis e outros meios de impugnação às decisões judiciais. São Paulo: Editora revista dos Tribunais, 2003.

LOPES, João Batista. Tutela antecipada no processo civil brasileiro. São Paulo: Saraiva, 2001 e Revista dos Tribunais (atual).

A Prova no Direito Processual Civil. São Paulo: Revista dos Tribunais, 2002.

Provas Atípicas e Efetividade do Processo. REDP - ANO 4 - 5o volume - Janeiro a Junho de 2010.

Tutela antecipada recursal. Tese Defendida do Doutorado pelo orientado Luís Henrique Barbante Franzé, PUC-SP.

OLIVEIRA; F.D. MACHADO (coord.). Constituição e processo: a contribuição do processo ao constitucionalismo democrático brasileiro. Belo Horizonte, Del Rey, p. 233-263.

ORIONE NETO, Luiz. Liminares no processo civil e legislação processual civil extravagante. 2a Ed. São Paulo: Editora Método, 2002.

MARINONI, Efetividade do Proceso e tutela de urgência, Porto Alegre, 1994.

Tutela Inibitória: a tutela de prevenção de ilícito. Editora Revista dos Tribunais, 2000. 
Tutela Inibitória" (individual e coletiva). Editora Revista dos Tribunais, 1998.

MOREIRA, José Carlos Barbosa. Processo civil e direito à preservação da intimidade. In: MOREIRA, José Carlos Barbosa. Temas de direito processual: segunda série. São Paulo: Saraiva, 1980. p. 3-20. MORAES. Alexandre de. Direito constitucional. 10a ed. São Paulo: Atlas, 2001.

NUNES, D.J.C. 2008. Processo jurisdicional democrático: uma análise crítica das reformas processuais. Curitiba, Juruá, $286 \mathrm{p}$.

PISANI, Andrea Proto. Nuovi diritti e tecniche di tutela, Scritti in onore di Elio Fazzalari. Milano, Giuffrè, 1993, v. 2, p. 51 e SS.

Brevi note in tema di tutela specifica e tutela risarcitoria. Foro Italiano, 1983.

L'effettività dei mezzi di tutela giurisdizionale con particolare riferimento all'attuazione della sentenza di condanna. Rivista di diritto processuale, 1975.

Lezioni di diritto processuale civile. Editora Jovene, 2006 .

RAPISARDA C. e TARUFFO M.“Inibitoria”, Enciclopedia Giuridica Trecani. v.17, p -1.

Inibitoria, digesto delle discipline privatistiche. v. 9, 1993, p. 480.

RICCI, G. 1995. Principi di Diritto Processuale Generale. Torino, Giappichelli, p -366.

SILVA, José Afonso da. Poder constituinte e poder popular; estudos sobre a constituição. 1ạ ed. São Paulo: Malheiros Editores, 2000.

Aplicabilidade das normas constitucionais. 3a ed. Malheiros Editores, São Paulo: 1998.

SCOGNAMIGLIO R. “Illecito”, novissimo digesto italiano. V.8, p. 169 e 1957, p. 201.

THEODORO JUNIOR, Humberto. Curso de direito processual civil. Editora Revista dos Tribunais, São Paulo, 2011.

Processo justo e contraditório dinâmico. Revista de Estudos Constitucionais, Hermenêutica e Teoria do Direito (RECHTD), 2(1):64-71 65. Estudo em homenagem ao Prof. Ovídio Baptista da Silva. Artigo publicado originalmente na Revista Magister de Direito Civil e Processual Civil, 33:518, nov-dez 2009 e Revista de Estudos Constitucionais, Hermenêutica e Teoria do Direito (RECHTD) 2(1): 64-71 janeiro-junho 2010, by Unisinos - doi: 10.4013/rechtd.2010.21.07.

Constituição e processo: desafios constitucionais da reforma do processo civil no Brasil. In: M.A.C. de, 2009b.

THEODORO JÚNIOR, H.; NUNES, D.J.C. Uma dimensão que urge reconhecer ao contraditório no direito brasileiro: sua aplicação como garantia de influência, de não surpresa e de aproveitamento da atividade processual. Revista de Processo, 2009, 168:107-141.

TROCKER, N. Processo civile e costituzione: problemi di diritto tedesco e italiano. Milano, A. Giuffrè , 768 p. (Studi di diritto comparato, 12), 1974.

I llimitti soggetivi del giudicato tra tecniche di tutela sostanziale e garanzie di difesa processuale. Rivista di Diritto Processuale, 1988, XLIII:35-95.

WAMBIER, Teresa Arruda Alvim. Parte Geral e Processo de Conhecimento. Vol. 1, 2a edição. Revista dos Tribunais, São Paulo, 2011.

Recursos e Ações Autonomas de Impugnação. Vol. 2, 2ª edição. Revista dos Tribunais, São Paulo, 2011. 
Terceiro no Processo Civil brasileiro e Assuntos Correlatos. Revista dos Tribunais, São Paulo, 2011.

Criticas ao Novo Projeto de CPC são senso comum. Revista Consultor Jurídico, em 27 de Junho de 2011.

WOOLF, L. 1996. Access to justice. Final Report to the Lord Chancellor on the civil justice system in England and Wales. London, HMSO, 139 p. e 192 p. 